\title{
Editorial
}

\section{Heiter \\ bis wolkig}

_Wenn da nicht diese dunkle Wolke über uns wäre. Taucht sie auf, droht ein Donnerwetter. Damit meine ich kein Wetterphänomen, sondern ein Delikt, das den Namen „Urheberrechtsverletzung“ trägt. Das Donnerwetter kann in Form von Abmahnungen oder Klagen erscheinen.

_ Auch durch unsere Redaktion zieht die Wolke von Zeit zu Zeit. Neulich wurde es beispielsweise kurzzeitig dunkel, als wir den Fall hatten, dass ein Autor in seinem Artikel Wissen einbeziehen wollte, das er in einer Fortbildung gelernt hat. Ist das erlaubt? In diesem Fall nicht. Denn dieses Wissen wurde „nur“ gelehrt und nie publiziert. Der Autor konnte es somit nicht zitieren. Literaturangaben sind aber wichtig, damit der Leser weiß, wo er den zugrunde liegenden Sachverhalt nachschlagen kann.

_ Aber nicht nur Artikel, sondern auch Unterrichts- oder Fortbildungsskripte sind hochgradig anfällig für Copyright-Verletzungen. Denn nicht immer entstammt das Verfasste dem Gedankengut des Skriptschreibers. Häufig ist es ihm gar nicht bewusst, dass er Abbildungen oder Inhalte anderer nicht einfach so „verarbeiten“ darf. Diese Wolke kann wirklich tückisch sein.

_ Das Urheberrecht erlischt übrigens erst 70 Jahre nach dem Tod des Urhebers. Das lässt erkennen, wie schützenswert geistiges Eigentum ist. Wettertechnisch lohnt es sich also durchaus, sich für das Thema „Copyright“ zu sensibilisieren.

Herzliche Grüße und erste Frühlingsstrahlen Ihre

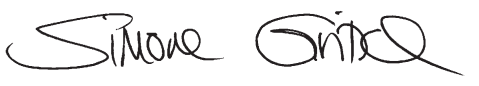

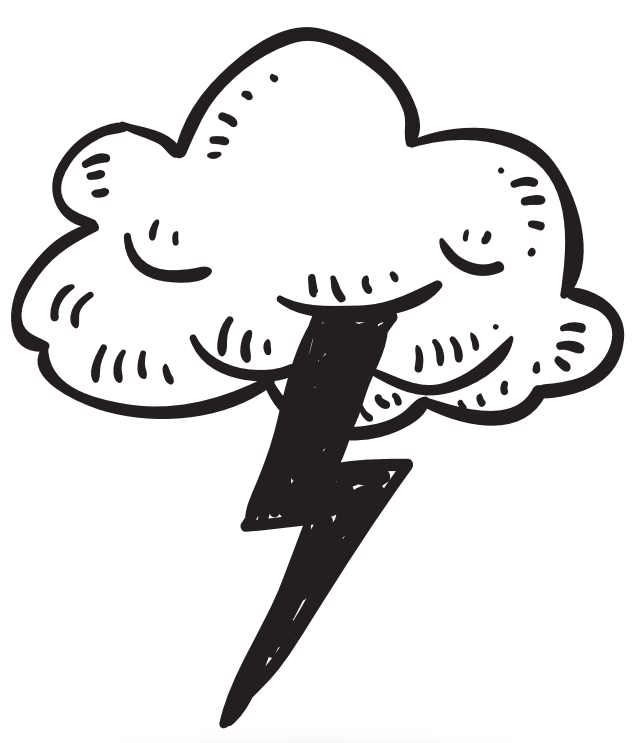

ZU GEWINNEN

Bücher

3-mal „Zu Hause

älter werden“

Seite 21

2 Pakete mit je einmal

„Baby-Shiatsu - Glücksgriffe

für Winzlinge“ und „Shiatsu für

Babys und Kleinkinder“ $\quad$ Seite 27

1-mal „Demenzen“

Seite 35

und außerdem ...

1 DVD „Vergiss mein nicht“ Seite 35

3 „AFH-Narbex Pflegegele“ Seite 38 